Rural electrification in Rwanda : A measure of willingness to contribute time and money

Thierry Kalisa

March 2014 


\section{GATE Groupe d'Analyse et de Théorie Économique Lyon-St Étienne}

93, chemin des Mouilles 69130 Ecully - France

Tel. +33 (0)4 72866060

Fax $+33(0) 472866090$

6, rue Basse des Rives 42023 Saint-Etienne cedex 02 - France

Tel. +33(0)4 77421960

Fax. +33 (0)4 77421950

Messagerie électronique / Email : gate@gate.cnrs.fr

Téléchargement / Download : http://www.gate.cnrs.fr - Publications / Working Papers 


\title{
Rural Electrification in Rwanda: A Measure of Willingness to Contribute Time and Money
}

\author{
Thierry Kalisa *
}

March 18, 2014

\begin{abstract}
This paper's motivation is to contribute to the growing literature on contingent valuation in developing countries. In a new survey in Rwanda valuing people's contribution for electrification, an innovative design is proposed, giving the choice to respondents between two scenarios: one in which they would contribute their time and another in which they would contribute their money. Results show that people prefer to contribute in time rather than in money. A great majority of people who have electricity would accept to contribute for the electrification of others. The potential contributors are willing to contribute $37,250 \mathrm{Frw}(\$ 55)$ and 66 days on average per year for five years.
\end{abstract}

Keywords: Contingent valuation, electrification, contribution, time

JEL Classification Numbers: D6, 013, 055, Q4, Q5

${ }^{*}$ Université de Lyon, Lyon, F-69007, France ; CNRS, GATE Lyon St Etienne, Ecully, F-69130, France(kalisa@gate@cnrs.fr). The author is grateful to Patrice Kalisa for all his support on the survey organization and comments on the paper, to Philippe Polomé and W. Douglass Shaw for advice, suggestions and comments. 


\section{Introduction}

This paper presents a relatively new contingent valuation (CV) design based on the choice of preferences given to respondents: contribute in terms of money or in terms of time for a particular volunteer work. This design is then applied to value rural households' contribution to obtain electricity based on a particularly ingenious and renewable source of energy in Rwanda.

The Contingent Valuation (CV) method is now widely used to value all kinds of goods: environmental, health and in general public goods. The principal attraction of the method is to obtain directly people's willingness to pay for both use and non-use values of a good or service. At first, some researchers were skeptical (Diamond and Hausman, 1994) because the CV method is based on an hypothetical scenario. However, the method is now better accepted. While the first CV studies were exclusively done in developed countries, they are becoming more frequent in developing countries. The topics are varied: access to water in Nigeria (Whittington et al., 1992), households' electrification in Kenya (Abdullah and Jeanty, 2011), national park conservation in Colombia (Alvarez and Larkin, 2010) or fishery restocking in a Lake of Cameroon (Fonta, Ichoku, and Nwosu, 2011) are some examples.

This paper presents a contingent valuation survey on people living in the districts of Karongi and Rubavu, Rwanda, close to Lake Kivu. Lake Kivu is located between Rwanda and the Democratic Republic of Congo, separating the two countries. This lake contains high concentrations of naturally occurring methane and carbon dioxide gases. A project called Kivuwatt, aims at extracting this methane gas from Lake Kivu and generate electrical power, that would benefit Rwandan people. The project has two main advantages: reduce the risks of explosion due to very high concentrations in methane gas on one hand and provide more electricity from a quasi-renewable source 
(RURA, 2013) ${ }^{1}$ on the other hand. The present survey asked people living close to the lake and directly concerned by the methane gas problem, how much they were willing to contribute to electrify all Karongi and Rubavu districts' households.

The National Oceanic and Atmospheric Administration (NOAA) panel report (Arrow et al., 1993) provides guidelines to implement a valid CV survey. This report is widely used by researchers when designing a new CV survey, and sometimes more attention may be paid to scrupulously respect it than to take into account the specificities of the country or population of study. Indeed, some questions seem of high importance: is it possible to conduct the exact same CV survey in a developed and in a developing country? If the willingness to pay value is found higher in a developed country for the exact same good than in a developing one, can we conclude that the former have a higher value for the good than the latter?

While the literature on CV in developing countries was growing, some researchers started to think about taking into account the specificities of these countries. Whittington (1998) is among those who think that a significant effort must be done to understand the local culture and to insure that the questionnaire is well understood by the respondents. This paper is in line with the idea that the contingent valuation must adapt to the country and population of study, and that a CV survey cannot be applied in a developing country the exact same way it is applied in a developed country. In fact, in developing countries in general, and in Sub-Saharan Africa in particular, the population has a low level of education and income. Whittington (1998) gives some recommendations: one should take into account the cultural and environmental differences in the country or region in question, much precaution should be made on the writing of the questions, and the survey must take the form of a face-to-face interview.

The second question challenges the use of the willingness to pay as the only measure of value for a good. In a developing country, the willingness to pay values would probably be lower compared to developing countries for

\footnotetext{
${ }^{1}$ The Lake Kivu methane gas reserves are estimated at around 55 billion cubic meters with an estimated renewal rate of about 120 million cubic meters every year.
} 
a given good, but that would not mean that people in these countries have lower interest in the good (Beder, 1996). This could happen simply because people are poorer and cannot afford to pay as much as in developed countries. Indeed, in these countries, income levels are often so low that they could not permit to fulfil people's basic needs. For example in Rwanda, where this paper's survey was made, 45 percent of the population is under the poverty line (WB, 2011). That is why, another instrument of measure is used in this paper: the willingness to contribute time (WTCT) in complement of the traditional willingness to contribute money (WTCM) or willingness to pay. Moreover, the notion of time contribution is well understood by Rwandan people since a law called Umuganda (RGB, 2013), requires a mandatory community service for every adult during at least one day per month.

The contribution in time is quite a new notion in CV literature. Larson, Shaikh, and Layton (2004) proposed a model with two binding constraints: time and money. In a CV survey, they obtained information on people's contributions in money and in time, a joint estimation of both types of responses permit to estimate a scarcity value of time. Based on this model, Londoño (2013) proposed an application to choice experiment method.

Alam (2006) used the term of Willingness to Contribute Time (WTCT) in a paper using data from a contingent valuation study valuing benefits of a river clean-up program in Bangladesh. First, questions about WTCM are asked and then WTCT (for some non-remunerated clean-up activities) questions irrespective of the first answer using a payment card. Tilahun et al. (2011) also use both monetary and time/labour payment vehicles in a contingent valuation for a forest conservation in Ethiopia. The authors use a classical double bounded dichotomous choice (DBDC) design, in which a second question is asked to the respondent after the initial bid if she is willing to accept a lower/higher bid, for both monetary and time questions.

This paper presents a new survey, whose objective is to evaluate people's contribution for electrification, but unlike Abdullah and Jeanty (2011), the focus is not only on non-electrified households: those who already have electricity may also be willing to contribute. If we suppose that they contribute mainly because they want to help others obtaining electricity, that contri- 
bution would mostly represent a non-use value. Two different scenarios are proposed: one in which the contribution is in time and the other in which the contribution is in money. The valuation questions are asked in terms of money and time using DBDC. In that, the survey design is similar to Tilahun et al. (2011). However, before the valuation questions, a simple question is asked about the preferred scenario or payment vehicle: "would you prefer to contribute time, money, or nothing?". With the modelling of this payment choice and the analysis of what variables influence this choice, this paper brings a contribution to the new literature on alternative payment vehicles for contingent valuation in developing countries. The survey could also help evaluate people's WTCT and WTCM for rural electrification in Rwanda, understand what variables influence these two types of contributions, and give some policy implications.

The results show that people tend to prefer a time contribution scenario rather than a money contribution one. Those who already have electricity have a lower probability to contribute compared to representatives of non electrified households. However, a majority of them do contribute for the electrification of others, but prefer the money scenario. The WTCM depends positively on the households' income: the wealthier is the household, the higher is the WTCM. Among the $89 \%$ of people who would accept to contribute, an average WTCM of 37,250 Frw (55 US $\$ \$^{2}$ ) is found as well as an average WTCT of 66 days $^{3}$ to give each year for five years in order to obtain electricity. In the next section, more details are provided on the survey.

\section{Survey and Data}

\subsection{Survey}

As explained in the introduction, the survey's area of study is the lake Kivu's region, especially the districts of Karongi and Rubavu in Rwanda.

\footnotetext{
${ }^{2} 2013$ exchange rate

${ }^{3}$ The answers to time and money questions have been treated separately
} 
Lake Kivu is one of the African great lakes located between Rwanda and the Democratic Republic of Congo, it covers 2,700 km². The lake and its islands are used for fishery and many recreational activities popular among the tourists: canoe, boat trips, campings... However, this lake also contains high levels of naturally occurring methane and carbon dioxide gases. If nothing is done, the lake could explode in 50 to 100 years causing inundations and toxic gas releases. By comparison, Lake Nyos in Cameroon, 2,000 times smaller than Kivu and also containing gases, experienced a limnic eruption (carbon dioxide erupted suffocated people nearby) that killed more than 1,700 people in 1986 (The Guardian, 2000).

A project called Kivuwatt, financed by private international investors and started in 2012, aims at constructing four offshore Gas Extraction Facilities barges, an onshore Power Plant and an onshore Marine Landing Site to extract methane gas from Lake Kivu and generate 100 Megawatts (MW) of electrical power. This electricity generated will then be sold to EWSA (National electric company of Rwanda) and benefit to rwandan people. The project has two main advantages: reduce the risks of explosion due to very high concentrations in methane gas on one hand and provide more electricity from a renewable source on the other hand. Nowadays, only $16 \%$ of Rwandan households have access to electricity (EWSA, 2013), but partly thanks to this new available electricity, the Rwandan government has the objective to raise this number to $70 \%$ by 2017 . EWSA's seven year plan is to exploit this gas more efficiently and generate a total of $350 \mathrm{MW}$, develop new hydro power plants delivering $230 \mathrm{MW}$, new geothermal power plants for $300 \mathrm{MW}$ and tap peat resources for $200 \mathrm{MW}$.

This study proposed to ask people living close to the lake and directly concerned by the methane gas problem, what they think about the Kivuwatt project and how much they are willing to contribute their money and/or time to electrify all Karongi and Rubavu districts' households once this electricity is available.

We used a non-probabilistic sampling method: we went to the different places to interview people at their home, on the streets or in public places. The population targeted was adult people (over 18 years old), who live in 
Karongi and Rubavu districts. Of course, we had one representative per household. The only rule was to have a representative sample of rwandan households in terms of electrification, that is why the interviewers were explicitly asked to have in the sample a proportion of about $16 \%$ of the respondents who have electricity at home. In that, our sample is representative of the Rwandan population in terms of electrification.

The survey took the form of face to face interviews. The questionnaire has been translated into Kinyarwanda, the local language, and administered by 14 local interviewers ${ }^{4}$, who were previously trained. To reach the target level of $16 \%$ of electrified households, we chose to interview people living in main towns where electricity is available as well as villagers who do not have access to electricity. Thus, $16 \%$ of our sample live in town. A pretest was run to test the questionnaire and the bid values on 70 people: 15 living in an electrified town, Kibuye (main town of the Karongi district), and 55 living in a village called Bwishyura, located close to Kibuye but that does not have electricity. Then, we administered the final questionnaire in six different places. In Karongi district, we went to Kibuye the town, Nyabihanga and Gitarama, which are two villages with no presence of electricity. In Rubavu district, we went to Gisenyi (main town of Rubavu district, electrified), Bisizi and Muri Haiti, two non electrified villages nearby. The villages and towns are all located very close to the lake, we exclude any distance effect.

The survey's questionnaire is divided into 5 parts. In part 1, we introduce ourselves and the context of the study. Then, we ask some questions about the presence of gas in the lake, the Kivuwatt project, and individual concern for an eventual pollution not related to the gas situation. This part also permits us to explain clearly the dangers of the presence of gas, its extraction and transformation into electricity before introducing the scenario. In part 2 , we introduce the scenario based on an hypothetical Non-Governmental Organisation (NGO) which would be created to help electrify the villages. Basically, we present two scenarios: one in which the NGO would raise funds from people's volunteer contributions in money and one in which it would need people's participation in time. This time would be spent doing some

\footnotetext{
${ }^{4}$ All completed high school, some of them study at university.
} 
non-remunerated work in order to electrify Rubavu and Karongi districts. The work could be physical: boundary work to materialize the new route of the power line, dig trenches in which the electric cables would pass... or non physical: cook food or bring water to the workers, participate in public awareness on the benefits of this new electricity...

The use of the NGO in the scenario is not trivial: a neutral organization would ensure us that we indeed evaluate people's behaviour devoid of any political or other reluctance. The appendix shows the scenario and valuation questions in details. Therefore, to summarize at this stage, the respondent has three choices: either contribute in money, in time, or not contribute at all. This choice determines the rest of the questionnaire.

Those who choose to contribute in money are first asked questions about their money contribution (WTCM): part 3 of the questionnaire. Then, we ask them to imagine that the money scenario is not available anymore and that it is only possible to contribute in time, and questions about time contribution (WTCT) are asked: part 4. Both valuations questions take the form of a Double Bid Dichotomous Choice (DBDC), which means that we first ask if the respondent accepts to pay or to give a particular amount of money or time (bid), then if the answer is yes, we ask another question for an increased bid and if it is no, we decrease the bid.

For those who prefer a contribution in time, we ask part 4 questions on time contribution before part 3 questions on money contribution. Therefore, whatever the type of contribution, every respondent is asked the same questions, the only thing that differs is the timing. Finally, for those who choose to not contribute at all, we directly ask the last part of the questionnaire: part 5 about demographic questions skipping parts 3 and 4, and the interview is over. Another important point is that we administer the same questionnaire to those who already have electricity at home. If we suppose that their main objective is more to help others obtaining electricity than safety, that contribution would represent mostly a non-use value in the sense that those people would contribute to an electricity which they would not benefit. 


\subsection{Data}

The survey was conducted in July-August 2013 and we ended up with a total workable sample of 487 people. People were in general available to answer to the questionnaire and except three of them, no one refused to answer ${ }^{5}$.

Table 1 presents the description and summary statistics of the main variables of the survey. As expected, a majority of people interviewed choose to contribute in time: $56 \%$. $33 \%$ of them prefer the money scenario and only $11 \%$ are not willing to contribute in any way. For those who chose not to contribute, by looking at their answers to some debriefing questions, the main reason is not that they do not want to contribute but they cannot: most of them consider themselves too poor, old or sick (57\%).

The average individual interviewed is between 31 and 40 years old, has been living in his current residence for more than 12 years and declared between 180,000 and 360,000 Frw (Rwandan Francs, local money) as the total yearly income of his household. This amount, equivalent to 267-534 US $\$$, represents the total of all incomes of the household per year. Discussing with people permitted us to understand that often, rural families depend on the income of only one person which is most of the time the father or one of the children who went to work in town. In general, people gladly answered to all the questions except the last one on the income for which some of them were reluctant. For this question, the answers were grouped in categories, therefore it seems reasonable to suppose that most of people answered truthfully. Since the level of income is very important in this study, it is important to keep it in the analysis, which reduced the sample from 487 to a final level of 444 people.

By looking at the other statistics of table 1, 64\% of people were aware of the presence of gas in the lake but only $38 \%$ knew about the Kivuwatt project of gas extraction. $88 \%$ of people are concerned or very concerned

\footnotetext{
${ }^{5}$ Women and old people are most likely to be found at their home in the morning. Men and employed people are easily found in meeting places like bars and restaurants especially at midday.
} 
about water pollution not due to the presence of gas in the lake ${ }^{6} .17 \%$ of people interviewed have electricity at home, which is representative of the Rwandan population (16\%). $51 \%$ are women, $64 \%$ are heads of their households and $65 \%$ declare to have a full-time activity ${ }^{7}$. The percentage of home owners is $80 \%$, the average household is composed of 5 people, and $18 \%$ declare having a business at home. Finally, $49 \%$ live in Karongi district, and $51 \%$ in Rubavu.

\section{The contribution choice: Results}

The first choice given to respondents: contribute in time, money or not contribute at all. 56\% answered time, 33\% answered money and 11\% answered nothing. In this part, the reasons of this choice are detailed. The econometric estimation is done using a multinomial logit. Table 2 presents what variables influence the decision of choosing time or money compared to not contributing at all.

We can observe that those who prefer to contribute in money or in time are younger than those who do not want to contribute. This is particularly true for some senior people (more than 65 years old) who explain that they do not have enough strength or money to contribute. The variable info gas is also significant in the two columns, which means that those who were aware of the presence of gas in the lake, prefer to contribute in money or time than to not contribute at all. Those ones could be considered to be more aware of the risks of the presence of gas in the lake, and therefore more willing to reduce them. Moreover, they could obtain electricity in exchange of this risk reduction. Similarly, those who are concerned about the lake pollution and those who have a business at home take more likely the decision to contribute, although the variables concern env and homebus are only significant at $10 \%$ in the case of time contribution.

\footnotetext{
${ }^{6}$ The average score is 4.26 out of 5 . The same proportion is concerned or very concerned about a future gas explosion. $95 \%$ has a good or very good opinion of the Kivuwatt project.

${ }^{7}$ Any type of activity not necessarily remunerated with a salary but that would occupy the person during a great part of the day, everyday: cultivating his/her own field, selling...
} 
The electricity variable is interesting: those who already have electricity at home are less willing to contribute than the representatives of the non electrified households, which is very understandable. Though, the high proportion $(87 \%)$ of people who have electricity and still want to contribute for others is quite surprising. This is slightly lower than for those who do not have electricity: $89 \%$, but still extremely high. Thus, the non-use value seems higher than expected. The debriefing answers show that some of the representatives of the electrified households are concerned about the risks of a gas explosion and want to reduce it, but for a majority of them, they want to help others: $35 \%$ contribute because they want electricity for others, $40 \%$ contribute because they want both electricity and safety and only $12 \%$ are only interested in safety. Thus we can consider this contribution as mainly a measure of non-use value ${ }^{8}$. It is also important to notice that in these regions, the link between people is very strong, many of the people living in towns have some relatives in the villages nearby who do not have access to electricity.

The size of the household is important for time contributors: the higher it is and the higher is the probability for the respondent to choose a time contribution over a null contribution. However, the household's size has no effect on those who choose money. On the contrary, the variable income is only significant in the money case: the wealthier is the household, the higher is the probability for the respondent to choose a money contribution over a null contribution. Income has no effect on the choice of time. This analysis helps us to understand what influences people's choice to contribute.

In order to analyse the choice between time and money contributions, the same multinomial logit estimation is done but with the money choice as the baseline outcome this time. Table 3 presents these results. Let us focus on the first column since the results of column "Nothing" have already been discussed before. We can observe that the time/money choice is explained by three variables: age, electricity and income.

\footnotetext{
${ }^{8}$ Among those who would contribute, regardless of whether they have electricity, $46 \%$ contribute because they want electricity, $43 \%$ contribute because they want both electricity and safety and only $5.5 \%$ are only interested in safety
} 
Older people tend to prefer the time scenario. As explained earlier, their probability to contribute is lower than younger individuals. However, from the debriefing questions and discussion, those who want to contribute estimate that they do not have enough money. Thus, they think that they could contribute by giving their time since most of them do not have any occupation. They are also more attracted to the non-physical activities described in the scenario because they do not estimate themselves strong enough to do some physical work.

The electricity coefficient confirms that those who have electricity, even if their probability to contribute is lower, tend to prefer a contribution in terms of money when they choose to contribute. It could be because those people might want to help others (non-use values) but their willingness to help is not large enough to engage in a volunteer's work, so they prefer to give an amount of money. Those people living in towns are also richer than the villagers who do not have access to electricity, thus they may prefer the money scenario because of that or they could consider the trip if they have to go work in the villages.

Finally, table 3 shows us that representatives of the poorest households, even if their probablity to contribute is lower, tend to prefer a time contribution over a money contribution when they choose to contribute: they want electricity but cannot afford to pay, so they would rather work.

The variable activity is surprisingly not significant in the model: we could think that those who have a full-time activity would be less willing to choose a contribution in time. However, an explanation could be found in the characteristics of the sample population: the rural population's main activity in Rwanda is Agriculture but there are few lands to cultivate compared to the size of the population (Rwanda has the highest population density level in Africa: 430 people per $\mathrm{km}^{2}$ ). Therefore, those who report themselves as "fulltime workers" are either farmers, or do a small business from farm products. The farmers do not work the whole year, they have some long periods where they do not cultivate, so they could think of this available time while answering to the scenario choice question. For non-farmers, as it is explained earlier, the majority of the population is extremely poor and electricity represents 
a huge development for them. Thereby, they could choose to renounce to their activities such as selling or be replaced by someone else who would be working at their place, so that they would dispose of enough time to work in order to obtain electricity. Indeed, some shop owners interviewed explained that they could let their children work at the shop while they go participate to the proposed activities. Finally, it is impossible to predict the sign of this activity variable: maybe these two effects cancel each other making the variable non significant.

The results presented so far gave us some clues to understand the contribution choice. In the next subsection, the focus will be made on what variables influence the amount of contribution in time (WTCT) or in money (WTCM) and how to value them.

\section{Willingness to Contribute Time and Money: Results}

In the survey, we asked four valuation questions: two for each scenario (time or money). Remember that depending on the first answer, a second question is asked raising or lowering the bid. For each scenario, a double-bounded interval data model (Hanemann, Loomis, and Kanninen, 1991; Haab and McConnell, 2003) is used to analyse these data. The idea is that answers to the two valuation questions give four probabilities to estimate: answering yes to the first and the second, yes to the first and no to the second, no and yes, and finally no and no.

The willingness to contribute time or money for individual $i$ can be written:

$$
W T C_{i}=\mu_{i}+\varepsilon_{i}
$$

where $\mu_{i}=X_{i} \beta$, for some variables $X$ and parameters $\beta$, and $\varepsilon_{i}$ is an error term.

Therefore, the WTC has a mean $\mu$ and a standard error noted $\sigma$. The 
probability for individual $i$ to answer yes to the first question's bid noted $B_{1}$ and yes to the second bid $B_{2}$ is:

$$
P_{i}^{y y}=\operatorname{Pr}\left(\mu_{i}+\varepsilon_{i}>B_{1}, \mu_{i}+\varepsilon_{i}>B_{2}\right)
$$

In this case, the second bid is higher than the first, so:

$$
P_{i}^{y y}=\operatorname{Pr}\left(\mu_{i}+\varepsilon_{i}>B_{2}\right)=\operatorname{Pr}\left(\frac{\varepsilon_{i}}{\sigma}>\frac{B_{2}-\mu_{i}}{\sigma}\right)=\Phi\left(\frac{\mu_{i}-B_{2}}{\sigma}\right)
$$

with $\Phi$, the cumulative density function of a normal distribution.

We can write the other three probabilities the same way.

The probability for individual $i$ to answer yes to the first question and no to the second is:

$$
P_{i}^{y n}=\operatorname{Pr}\left(\mu_{i}+\varepsilon_{i}>B_{1}, \mu_{i}+\varepsilon_{i}<B_{2}\right)
$$

So,

$$
P_{i}^{y n}=\operatorname{Pr}\left(B_{1}<\mu_{i}+\varepsilon_{i}<B_{2}\right)=\Phi\left(\frac{\mu_{i}-B_{1}}{\sigma}\right)-\Phi\left(\frac{\mu_{i}-B_{2}}{\sigma}\right)
$$

The probability for individual $i$ to answer no to the first question and yes to the second is:

$$
P_{i}^{n y}=\operatorname{Pr}\left(\mu_{i}+\varepsilon_{i}<B_{1}, \mu_{i}+\varepsilon_{i}>B_{2}\right)
$$

So,

$$
P_{i}^{n y}=\operatorname{Pr}\left(B_{2}<\mu_{i}+\varepsilon_{i}<B_{1}\right)=\Phi\left(\frac{\mu_{i}-B_{2}}{\sigma}\right)-\Phi\left(\frac{\mu_{i}-B_{1}}{\sigma}\right)
$$

The probability to answer no to both bids is:

$$
P_{i}^{n n}=\operatorname{Pr}\left(\mu_{i}+\varepsilon_{i}<B_{1}, \mu_{i}+\varepsilon_{i}<B_{2}\right)
$$


In this case, the second bid is lower than the first, so:

$$
P_{i}^{n n}=\operatorname{Pr}\left(\mu_{i}+\varepsilon_{i}<B_{2}\right)=\operatorname{Pr}\left(\frac{\varepsilon_{i}}{\sigma}<\frac{B_{2}-\mu_{i}}{\sigma}\right)=\Phi\left(\frac{B_{2}-\mu_{i}}{\sigma}\right)
$$

Finally, we can write the following log-likelihood function:

$$
L=\sum_{i=1}^{N}\left[I^{y y} \ln P_{i}^{y y}+I^{y n} \ln P_{i}^{y n}+I^{n y} \ln P_{i}^{n y}+I^{n n} \ln P_{i}^{n n}\right]
$$

where $I$ are indicator variables: $I^{y y}$ for example is equal to 1 if the respondent answered yes to both questions.

A STATA command called "doubleb" (Lopez-Feldman, 2010) estimates directly this log-likelihood function. Table 4 presents the results of this estimation for all the contributors of the two scenarios irrespective of the contribution preference. Thus, the fist column shows the results of a classical double-bounded interval data analysis usually used to modelize willingness to pay on all respondents who answered to the two valuation questions in money. Similarly, the second column presents the results of the same model applied to time answers. However, it is necessary to explain why the contribution choice is not taken into account in this analysis. The next section explains the reasons.

The first column shows that among those who accept to contribute in money or in time, older people are willing to give less money. Remember the last results: older people's probability to contribute is lower and for those who want to contribute, they prefer a time contribution. Thus, it is somewhat logical that they are less likely to accept to pay. The WTCM is also lower for owners (only at 10\%), for those living in the Karongi disctrict, and for those who have electricity at home. As explained earlier, these latter ones have a lower probability to contribute even if the contributors prefer a money scenario. An explanation could be that those who accept to contribute, want to make a small contribution in money: they do not want to give zero because they think it is important for others in the villages to have electricity, but their WTCM is significantly lower than for the main stakeholders that are the non electrified households. 
On the contrary, people who have a business at home are willing to pay more. We have seen previously that those people prefer to contribute in money or time rather that not doing anything. Similarly, we can observe that the WTCM is larger for those who are aware of the Kivuwatt project, for those who have been living in their current residence for a relatively long period of time, and for the representatives of the wealthier households. The latter ones have previously been found to prefer a money contribution over a time contribution and nothing.

The second column of table 4 shows the results of the WTCT estimation. Three variables are important: info gas, electricity and homebus. Having electricity at home affects negatively the number of days of work. Remember that those who have electricity prefer to give money. Thus, while answering to questions about time, they are less likely to answer yes. Having a business at home and being aware of the gas situation in the lake increases the number of days given for volunteer's works. Those two categories of people tend to prefer a contribution in time or money over a null contribution.

The average WTCM is 37,250 Frw, which represents about $\$ 55^{9}$ to give each year for five years in order to obtain electricity. This value has to be interpreted with caution since it does not represent everyone in the population, but only those who are willing to contribute in time or money. All things being equal, those who already have electricity are willing to contribute 18,925 Frw (\$28), which is in great part a non-use value.

The average WTCT is about 66 days, which means that people on average are willing to work for 66 days per year, a little more than one day per week, during five years in order to obtain electricity. There is almost no other study which incorporates time in valuing households' electrification, so no other number to compare to. At first, this number can appear to be very high, but again the context of the country can help us understand why people are so willing to contribute. As explained earlier, people interviewed consider electricity as a very important development of their localities and are very willing to contribute. The lack of money, combined with the availability of time explains this high number of days: the farmers have some long periods

${ }^{9} 2013$ exchange rate 
of inactivity, and non-farmers could choose to renounce to some of their activities or find another solution to be available.

Another explanation is the Umuganda: this law that requires a mandatory community service for every adult during one day per month in urban areas. People in the urban context, represented in this survey by those who already have electricity, are only willing to contribute 16 days per year, a little more than one day per month which is the normal length of the Umuganda. However, sometimes in rural cities, the Umuganda asks people to work more for some particular actions that would increase their welfare or comfort. Thus in the rural context, people are used to do more community service and could see what we are asking them as another community service which would lead to obtain electricity, something they want very much.

Table 5 present the WTCT and WTCM depending on the choice to contribute some time or some money. Among contributors, those who prefer to give some time are willing to contribute less money than those who prefer a money contribution (the amounts are significantly different). Similarly, those who prefer time are willing to contribute more time than those who prefer a contribution in money.

\section{Discussion: the contribution decision, en- dogeneity and selection bias}

The results of table 5 show that the amounts of WTCM and WTCT depend strongly on the decision to contribute in money or time. So, this variable should have logically been included in the model. However, maybe it does not necessarily make sense to use the contribution choice as an explanatory variable in the WTCT or WTCM model. In fact, the valuation questions are somehow a refinement of the first question, we are asking for more precision. To caricature what we do, we first ask what the person prefers between time and money, then we ask him/her how much. Thus, the two questions could be seen as basically the same, the only difference is that the second one gives more information. 
If we suppose that the contribution choice should have been included anyway, there would be another problem: this variable is most likely endogenous. As table 3 shows, the contribution choice is well explained by the age, electricity status and income. Some methodologies exist to treat endogeneity but they almost all require some strong excluded instruments (Lewbel, Dong, and Yang, 2012): variables that are correlated with the contribution choice but not with the amount of this contribution. There is a contradiction here, how is it possible to find a variable that could explain a preference for time or money contribution and that would have no effect on the amount of time or money contributed? As table 4 shows, the variables age, income and electricity are again significant in the DBDC estimation. The recent special regressor approach presented by Lewbel (1998) could treat this endogeneity problem with weaker instruments. However, no instruments are available here and this approach would be incompatible with double bounded data and multinomial logit analyses. To summarise, there is a problem of endogeneity, problem that seems impossible to solve.

For the same reasons as above, the decision to contribute or not cannot be used as a regressor. The problem is that the sample auto selects for the rest of the questionnaire, since those who do not want to contribute are not asked the valuation questions. There is a sample selection issue, that is why some precaution has to be taken while generalizing the amounts of WTCT and WTCM for the whole population. However, the sample selection issue is on very few people since almost $90 \%$ of the population agree to contribute, so we could estimate that our results are not biased.

\section{Conclusion}

This paper's motivation is to contribute to the growing literature on contingent valuation in developing countries. In a new CV survey in Rwanda valuing people's contribution for electrification, a relatively new design is proposed giving the choice to respondents between two scenarios: one in which they would contribute their time and another in which they would contribute their money. We found that people prefer to contribute in time 
rather than in money. People who have electricity at home have a lower probability to contribute compared to those who do not. However, a great majority of them do contribute for the electrification of others, but they prefer to give money. Also, wealthier households contribute a higher amount of money. Among the $89 \%$ of people who contribute, the results show an average WTCM of 37,250 Frw (\$55) and an average WTCT of 66 days to give each year for five years in order to obtain electricity. Those who prefer time have a higher WTCT and those who prefer to give money have a higher WTCM.

It is difficult to find benchmarks since contingent valuation surveys evaluating rural electrification are very rare. But if we compare this study to Abdullah and Jeanty (2011) study, using a contingent valuation survey to value rural households' electrification of non-electrified households in Kenya, there is a significant difference between their willingness to pay value and the WTCM value found in this paper: they find a willingness to pay of about $\$$ $116^{10}$ per year, which is more than twice higher than ours.

However, it is quite impossible to obtain a corresponding monetary value for our high WTCT (66 days). Indeed, the common point between for example Feather and Shaw (1999) who proposed an approach for determining the opportunity cost of leisure time in a travel cost framework, and Larson, Shaikh, and Layton (2004) who monetized a time contribution in a CV framework is that they both use information about the wage. In our study, we do not have any information about wages. In addition, there is a huge unemployment rate $(22.7 \%)$ in such rural areas in Rwanda (NISR, 2012), and a lack of data about wages in general. There is also no minimum wage defined by the law and this unemployment is also in the majority of cases involuntary: people explain that they would like to work, but no work is available ${ }^{11}$.

Thus, it is impossible to give a good measurement of WTCT in money value. However, just to have a small idea, when installing electricity in

\footnotetext{
${ }^{10} 2013$ exchange rate Ksh/USD

${ }^{11}$ We asked people is they have a full-time "activity", but that does not mean they are employed, activity could be selling milk or cultivating, the revenues are difficult to estimate.
} 
a village, EWSA (electrical company) use laborer to dig trenches and do the physical activities described in the scenario. These laborers are paid 2,000 Frw per day. Thus, if the respondents to the survey were paid the same amount for the time they give, the average WTCT converted in money would then be equivalent to 132,000 Frw (\$196) per year, which is more than three times the average contribution in money. Even if this conversion is not accurate, our very high WTCT value of 66 days comforts us in the idea that relying only on the willingness to pay to evaluate a good in a developing country context could lead to underestimate the true contribution of people who are poor, but can give more than their money. Tilahun et al. (2011) also find in their study high values for the time contribution (higher than the money contribution).

The results of this study show that people interviewed really need electricity and are convinced that it would develop their village, they are extremely poor but are willing to contribute as much as they can. EWSA or the Rwandan government could think of a price strategy that would include their work or participation in the electricity installation, or permit them to pay every year or semester instead of a lump sum. Local officials could also think of including the future work of electricity installation in the Umuganda schedule, since the great majority accepts to contribute.

One limit of this paper is that it is not possible to convert the amount of WTCT into money: in future works, an idea could be to directly ask people about their minimum wage for the proposed activities.

\section{References}

Abdullah, S., and W. Jeanty. 2011. "Willingness to pay for renewable energy: Evidence from a contingent valuation survey in Kenya." Renewable and Sustainable Energy Reviews 15:2974-2983.

Alam, K. 2006. "Valuing the environment in developing countries: Problems and potentials." Asia Pacific Journal on Environment and Development $13: 27-44$. 
Alvarez, S., and S.L. Larkin. 2010. "Valuing ecological restoration and recreational benefits in a mountain protected area: The case of Los Nevados national park, Colombia." Journal of Sustainable Development 3(4).

Arrow, K., R. Solow, P. Portney, E.E. Leamer, R. Radner, and H. Schuman. 1993. "Report of the NOAA Panel on Contingent Valuation." Federal Register 58:4602-4614.

Beder, S. 1996. "Valuing the Environment." Engineering World, pp. 12-14.

Diamond, P.A., and J.A. Hausman. 1994. "Contingent valuation: is some number better than no number?" The Journal of Economic Perspectives $8(4): 45-64$.

EWSA. 2013. "Energy, Water and Sanitation Authority, Rwanda." http: //www. ewsa.rw/.

Feather, P., and W.D. Shaw. 1999. "Estimating the cost of leisure time for recreation demand models." Journal of Environmental Economics and Management 38:49-65.

Fonta, W.M., H.E. Ichoku, and E. Nwosu. 2011. "Contingent valuation in community-based project planning: The case of lake Bamendjim fishery restocking in Cameroon." Working paper, African Economic Research Consortium (AERC) Research Paper210.

Haab, T.C., and K.E. McConnell. 2003. Valuing environmental and natural resources:, W. E. Oates and H. Folmer, eds. Edward Elgar Publishing.

Hanemann, M., J. Loomis, and B. Kanninen. 1991. "Statistical efficiency of double-bounded dichtotomous choice contingent valuation." American Journal of Agricultural Economics 73:1255-1263.

Larson, D.M., S.L. Shaikh, and D.F. Layton. 2004. "Revealing preferences for leisure time from stated preference data." American Journal of Agricultural Economics 86(2):307-320. 
Lewbel, A. 1998. "Semiparametric latent variable model estimation with endogenous or mismeasured regressors." Econometrica 66:105-121.

Lewbel, A., Y. Dong, and T.T. Yang. 2012. "Comparing Features of Convenient Estimators for Binary Choice Models With Endogenous Regressors." Working paper, forthcoming Canadian Journal of Economics.

Londoño, C. 2013. "Using choice experiments to value preferences over stormwater management." $\mathrm{PhD}$ dissertation, University of Illinois at Urbana-Champaign.

Lopez-Feldman, A. 2010. "STATA module to compute Contingent Valuation using Double-Bounded Dichotomous Choice." http://ideas.repec.org/c/boc/bocode/s457168.html.

NISR. 2012. "National Institute of Statistics of Rwanda." http://statistics.gov.rw/publications/article/ employment-rate-higher-women-men-rwanda.

RGB. 2013. "Rwanda Governance Board." http://www.rgb.rw/main-menu/ innovation/umuganda.html.

RURA. 2013. "Rwanda Utilities and Regulatory Authority." http://www.rura.rw/index.php?id=92.

The Guardian, J. 2000. "The world's most deadly bubble." http://www. theguardian. com/world/2000/aug/20/theobserver1.

Tilahun, M., E. Mathijs, B. Muys, L. Vranken, J. Deckers, K. Gebregziabher, K. Gebrehiwot, and H. Bauer. 2011. "Contingent valuation analysis of rural households' willingness to pay for Frankincense forest conservation." Working paper, EAAE 2011 Congress Change and Uncertainty.

WB. 2011. "World Bank Data: Rwanda." http://data.worldbank.org/country/rwanda.

Whittington, D. 1998. "Administering contingent valuation surveys in developing countries." World Development 26:21-30. 
Whittington, D., V.K. Smith, A. Okorafor, A. Okore, J.L. Liu, and A. McPhail. 1992. "Giving respondents time to think in contingent valuation studies: a developing country application." Journal of Environmental Economics and Management 22:205-225. 
Table 1. Variable description and Summary statistics

\begin{tabular}{|c|c|c|c|}
\hline Variable & Description & Mean & Std. Dev. \\
\hline Time & Contribute in Time (dummy) & 0.56 & 0.5 \\
\hline Why notcont & $\begin{array}{l}\text { Refuses contribution because too poor, } \\
\text { old or sick (dummy) }\end{array}$ & 0.57 & 0.24 \\
\hline Age & Categorized age variable, normalized & $31-40$ & \\
\hline Info gas & Knew about the presence of gas (dummy) & 0.64 & 0.48 \\
\hline Info kivuwatt & Knew about the Kivuwatt project (dummy) & 0.38 & 0.49 \\
\hline Concern env & $\begin{array}{l}\text { From 1: Not concerned at all about water pol- } \\
\text { lution not due to the gas, to } 5 \text { : Very concerned }\end{array}$ & 4.26 & 0.88 \\
\hline Electricity & Has electricity at home (dummy) & 0.17 & 0.38 \\
\hline Gender & Woman (dummy) & 0.51 & 0.5 \\
\hline Househead & Head of the household (dummy) & 0.64 & 0.48 \\
\hline Activity & Has a full-time activity (dummy) & 0.65 & 0.48 \\
\hline Own & Owns his/her residence (dummy) & 0.8 & 0.4 \\
\hline House & Number of people living in the same residence & 5 & 2.25 \\
\hline Curesid & Number of years living in the current residence & 12.28 & 14.92 \\
\hline Homebus & Has a business activity at home (dummy) & 0.18 & 0.38 \\
\hline Income & Categorized income variable & $180-360$ & \\
\hline Karongi & 1: Lives in Karongi district, 0: Rubavu (dummy) & 0.49 & 0.5 \\
\hline
\end{tabular}

For dummy variables, description is given for the value 1 
Table 2. The contribution: Time and Money compared to Nothing

\begin{tabular}{lcccc}
\hline \multicolumn{2}{c}{ Money } & \multicolumn{2}{c}{ Time } \\
\hline Intercept & -2.009 & $(1.25)$ & 0.124 & $(1.153)$ \\
Age & $-0.811^{* * *}$ & $(0.193)$ & $-0.498^{* * *}$ & $(0.15)$ \\
Info gas & $1.362^{* * *}$ & $(0.49)$ & $1.266^{* * *}$ & $(0.454)$ \\
Info kivuwatt & -0.002 & $(0.478)$ & -0.259 & $(0.458)$ \\
Concern env & $0.446^{* *}$ & $(0.226)$ & $0.367^{*}$ & $(0.207)$ \\
Electricity & $-1.185^{* *}$ & $(0.564)$ & $-2.062^{* * *}$ & $(0.559)$ \\
Gender & 0.043 & $(0.419)$ & 0.387 & $(0.396)$ \\
Activity & -0.274 & $(0.448)$ & -0.275 & $(0.419)$ \\
Own & -0.347 & $(0.561)$ & -0.733 & $(0.529)$ \\
House & 0.165 & $(0.106)$ & $0.245^{* *}$ & $(0.101)$ \\
Curesid & 0.024 & $(0.015)$ & 0.014 & $(0.014)$ \\
Homebus & $1.763^{* *}$ & $(0.791)$ & $1.521^{*}$ & $(0.781)$ \\
Income & $0.485^{* *}$ & $(0.191)$ & -0.186 & $(0.197)$ \\
\hline 0.1, ** 0.05, *** 0.01 significance. Standard errors are between parenthesis.
\end{tabular}


Table 3. The contribution: Time and Nothing compared to Money

\begin{tabular}{lcccc}
\hline \multicolumn{2}{c}{ Time } & \multicolumn{2}{c}{ Nothing } \\
\hline Intercept & $2.132^{* * *}$ & $(0.786)$ & $2.009^{*}$ & $(1.25)$ \\
Age & $0.313^{* *}$ & $(0.149)$ & $0.811^{* * *}$ & $(0.193)$ \\
Info gas & -0.096 & $(0.288)$ & $-1.362^{* * *}$ & $(0.49)$ \\
Info kivuwatt & -0.257 & $(0.265)$ & 0.002 & $(0.478)$ \\
Concern env & -0.079 & $(0.142)$ & $-0.446^{* *}$ & $(0.226)$ \\
Electricity & $-0.877^{* *}$ & $(0.36)$ & $1.185^{* *}$ & $(0.564)$ \\
Gender & 0.344 & $(0.239)$ & -0.043 & $(0.419)$ \\
Activity & -0.001 & $(0.258)$ & 0.274 & $(0.448)$ \\
Own & -0.386 & $(0.327)$ & 0.347 & $(0.561)$ \\
House & 0.08 & $(0.056)$ & -0.165 & $(0.106)$ \\
Curesid & -0.01 & $(0.009)$ & -0.024 & $(0.015)$ \\
Homebus & -0.242 & $(0.294)$ & $-1.763^{* *}$ & $(0.791)$ \\
Income & $-0.672^{* * *}$ & $(0.122)$ & $-0.485^{* *}$ & $(0.191)$ \\
\hline \% & ** $0.05, * * * 0.01$ significance. Standard errors are between parenthesis.
\end{tabular}


Table 4. Double bounded interval data analysis on time and money dichotomous answers

\begin{tabular}{lcccc}
\hline \multicolumn{2}{c}{ Money } & \multicolumn{2}{c}{ Time } \\
\hline Intercept & $19.386^{* *}$ & $(7.874)$ & $61.422^{* * *}$ & $(12.44)$ \\
Age & $-5.951^{* *}$ & $(2.573)$ & 1.950 & $(3.777)$ \\
info gas & 2.520 & $(5.268)$ & $17.771^{* *}$ & $(8.351)$ \\
Info kivuwatt & $22.578^{* * *}$ & $(5.18)$ & 0.085 & $(8.263)$ \\
Electricity & $-21.717^{* * *}$ & $(6.906)$ & $-60.615^{* * *}$ & $(11.258)$ \\
Househead & -4.408 & $(4.639)$ & -3.481 & $(7.362)$ \\
Own & $-10.073^{*}$ & $(5.796)$ & -3.821 & $(9.349)$ \\
Curesid & $0.54^{* * *}$ & $(0.168)$ & 0.009 & $(0.268)$ \\
Homebus & $11.305^{* *}$ & $(5.591)$ & $22.777^{* *}$ & $(9.296)$ \\
Income & $11.573^{* * *}$ & $(2.085)$ & -0.216 & $(3.093)$ \\
Karongi & $-10.601^{* *}$ & $(4.684)$ & 5.45 & $(7.333)$ \\
WTCM & $37,250.44^{* * *}$ & $(1063.107)$ & & \\
WTCT & & & $66.04^{* * *}$ & $(1.238)$ \\
\hline 1, ** 0.05, *** 0.01 significance. Standard errors are between parenthesis.
\end{tabular}


Table 5. WTCT and WTCM

\begin{tabular}{lcc}
\hline & Money preference & Time preference \\
\hline WTCM & $45,791.92$ & $31,769.67$ \\
& {$[42,204.43,49,379.39]$} & {$[18,16492,29,459.84]$} \\
WTCT & 58.93 & 70.52 \\
& {$[54.17,63.69]$} & {$[68.06,72.98]$} \\
\hline
\end{tabular}

95\% Student t-based Confidence intervals are between parenthesis. 


\section{Appendix: The questionnaire's scenario and economic valuation}

(English version translated from French, the administered questionnaire was in Kinyarwanda)

\section{The Scenario}

9. The first part of this electricity produced from the gas extraction will be available in 2014. Now suppose that an NGO is created in your district and works to electrify all the villages in Karongi and Rubavu districts by 2018. There are 2 possibilities:

- This NGO would raise funds and form a common fund with people's volunteers' contributions. Without these contributions, the target could not be reached. You and every household would be asked for your contribution in money. In this case, we would like to know your willingness to pay for the electrification of communities who do not have electricity in the districts of Karongi and Rubavu.

- This NGO created to electrify all the villages in Karongi and Rubavu districts by 2018 will not need money, but people's contributions in labor. Please notice that these activities would not be part of the Umuganda. The different activities could be physical: transport of electric wires, boundary work to materialize the new route of the power line, dig trenches in which the electric cables would pass, transport and installation of electric poles... or non physical: cook food or bring water to the workers, surveillance to avoid theft or destruction of equipment, participate in public awareness on the benefits of this new electricity, or on the use and way to connect to the new grid... In this case, we would like to know your willingness to contribute your time for some non remunerated activities for the electrification of communities who do not have electricity in Karongi and Rubavu districts.

Would you prefer to contribute your money, your time or nothing?

Money $\square$ Time $\square \quad$ None of them 
No answer

\section{Willingness to Contribute Money}

10. The NGO created would need your contribution in money. Similar studies show that often people answers differ from their actual behavior. Indeed, they sometimes argue that they would be willing to pay a certain amount. However, they do not think seriously about the real impact of this amount on their household's budget. We would like that you consider this point seriously and answer like if you really had to pay this amount.

So, would you be willing to pay X Frw per year, participating into the common fund, during 5 years to show your support to the initiative and help connect all Karongi and Rubavu districts' households to electricity?

Please note that means you would have to save X/12 Frw per month to pay this $\mathrm{X}$ once in a year. Moreover, your future electricity consumption is not included and we will not be the ones who will bring electricity.

Your contribution would start in 2014 and end in 2018 (5 years). You would first have to start paying before electricity arrive in a maximum of 5 years. If a majority of people interviewed is willing to pay the amount of money necessary, the gas extraction and transformation into electricity will permit to all communities living in Karongi and Rubavu districts to have access to electricity by 2018. If not, the situation would remain the same as today's, and you would not pay anything.

Yes $\square \quad$ No $\square \quad$ No answer $\square$

(If yes, go to 11., If no, go to 12.)

\section{Willingness to Contribute Time}

13. The NGO created would need your contribution in time. Remember the different activities could be physical: transport of electric wires, boundary work to materialize the new route of the power line, dig trenches in which the electric cables would pass, transport and installation of electric poles... or non physical: cook food or bring water to the workers, surveillance to avoid 
theft or destruction of equipment, participate in public awareness on the benefits of this new electricity, or on the use and way to connect to the new grid... You would not have to pay any transport or other fees. Please notice that these activities would not be part of the Umuganda. Similar studies show that often people answers differ from their actual behavior. Indeed, they do not think seriously about the real impact of the given time on their total available time, especially that giving away this time would lead to less time for leisure, and family activities. We would like that you consider this point seriously and answer like if you really have to spend this time for the activities described.

So, would you be willing to contribute $\mathrm{T}$ days per year of your time, into non remunerated activities, during 5 years to show your support to the initiative and help connect all Karongi and Rubavu districts' households to electricity?

The number of days proposed are not exhaustive and you may still decide to do more if you want. Please note your future electricity consumption is not included and we will not be the ones who will bring electricity. Your contribution would start in 2014 and end in 2018 (5 years). You would first have to start working before electricity arrive in a maximum of 5 years.

If a majority of people interviewed is willing to contribute enough time, the gas extraction and transformation into electricity will permit to all communities living in Karongi and Rubavu districts to have access to electricity by 2018. If not, the situation would remain the same as today's.

$\begin{array}{lll}\text { Yes } \square & \text { No } \square & \text { No answer } \square\end{array}$

(If yes, go to 14., If no, go directly to 15.) 